\title{
Psychological Factors Influencing Exercise Adherence among Females
}

\author{
Sarah S. Kohlstedt, Carol S. Weissbrod, Anna M. Colangelo, Michele M. Carter \\ The American University, Washington, D.C., USA \\ Email: cweissb@american.edu
}

Received September $20^{\text {th }}, 2013$; revised October $21^{\text {st }}, 2013$; accepted November $18^{\text {th }}, 2013$

\begin{abstract}
Copyright (C) 2013 Sarah S. Kohlstedt et al. This is an open access article distributed under the Creative Commons Attribution License, which permits unrestricted use, distribution, and reproduction in any medium, provided the original work is properly cited. In accordance of the Creative Commons Attribution License all Copyrights (C) 2013 are reserved for SCIRP and the owner of the intellectual property Sarah S. Kohlstedt et al. All Copyright $(\mathcal{C} 2013$ are guarded by law and by SCIRP as a guardian.
\end{abstract}

\begin{abstract}
Social pressures focusing on health and physical attractiveness have been used to promote exercise among women (Prichard \& Tiggemann, 2008). However, research has shown that motives driven by external sources result in decreased exercise participation (Deci \& Ryan, 1985). The current study examined differences in motivation, self-efficacy, and mood between 64 exercise adherent and non-adherent women over four weeks. Women who were non-adherent to their exercise goals were more likely to report external motives, specifically body and health related motives. At the initial measurement, adherents reported significantly lower self-efficacy, positive affect, and life satisfaction compared to non-adherents. However, after the four weeks, adherents' self-reports indicated a significant increase in these variables compared to no change in non-adherents' self-reports.
\end{abstract}

Keywords: Gender; Motivation; Physical Self-Efficacy; Self-Determination; Exercise

\section{Introduction}

Physical inactivity remains a serious issue in our society, particularly for women. Despite continued health education, more than $60 \%$ of American women do not engage in recommended levels of physical activity, and more than $25 \%$ are completely sedentary (Center for Disease Control, 2010). Among individuals who do initiate exercise programs, approximately half drop out during the first six months (Dishman, 1990; Sallis et al., 1992). The importance of persistence in exercise, coupled with the low numbers of women who are persistent in exercise, suggests a need to determine what differentiates women who are adherent and non-adherent to physical activity. Research has demonstrated that social pressures for health and physical attractiveness may be used to promote exercise and fitness for women (Blaine \& McElroy, 2002; Prichard \& Tiggemann, 2008); however, while this external motivation may help initiate exercise, research findings have shown a negative association with persistence (Teixeira et al., 2006; Young et al., 2001). The current study sought to determine if female participants who adhered to their exercise goal over a four-week period differed in their expressed motivation for exercise from female participants who did not adhere to their goal. In addition, the study explored differences between the two groups in physical self-efficacy, positive affect, and satisfaction with life.

The theory of self-determination (SDT; Deci \& Ryan, 1985) offers an explanation for differences in adherence to exercise. SDT is based on the assumption that the choices an individual makes are driven by self-determined motives and/or externally determined motives. Typically, when exercise goals are self- determined, they reflect intrinsic motivation based on enjoyment, competence, and social interaction. Research has demonstrated that this kind of motivation is correlated with exercise intentions and exercise adherence, particularly in women (Centers for Disease Control, 2010; Edmunds et al., 2007; Izquierdo-Porrera et al., 2002; Prichard \& Tiggemann, 2008; Teixera et al., 2006; Wankel, 1993; Wilson \& Rodgers, 2004). When goals are not self-determined, but rather, introjected or controlled, they reflect motivation that is driven by external sources; in general, research findings have demonstrated that this kind of motivation undermines the development of autonomy, and is therefore not optimal for sustaining an intentional physical activity routine (Ryan \& Deci, 2000; Ryan et al., 1997; Segar et al., 2006). Presumably, when individuals feel pressured to exercise, they lack the enjoyment and inner motivation to continue, causing them to discontinue their behavior.

Women often report that their motivation to exercise is based on body-related concerns (Anderson, 2003; Berman et al., 2005; Finkenberg et al., 1994; Gill \& Overdorf, 1994; Markland \& Ingledew, 2007; Tiggemann \& Williamson, 2000), which reflect an external or interjected pressure. For example, Berman and colleagues (2005) reported that women endorsed weight and body related reasons for exercise, and though they did exercise, they continued to experience body dissatisfaction, preoccupation with weight, and poor emotional well-being. Importantly, Kilpatrick, Hebert, and Bartholomew (2005) suggest that women report weight management as a motivation for exercise more often than do men, which may make them particularly susceptible to exercise non-adherence.

In addition to gender differences, the type of motivation also seems to vary by a woman's age group. Scharff, Homan, Kreu- 
ter, and Brennan (1999) found that younger women were more likely to report weight management as their primary motivation for being physically active while older women were more likely to indicate health as their main motivation. Different results based on age group were also noted in Tiggemann and Williamson (2000). Their data supported a positive relationship between exercise engagement and psychological well-being among older women, while among younger women there was an inverse relationship between exercise and well-being.

Results from other research have indicated that body-related motives are not only associated with social physique anxiety, depression, anxiety, reduced self-esteem, and body dissatisfaction (Frederick \& Morrison, 1996; Prichard \& Tiggemann, 2008; Strelan et al., 2003), but also with less exercise participation (Segar et al., 2006; Segar et al., 2008). It seems that bodyrelated motives may decrease women's sense of autonomy and self-determination, giving rise to obligatory exercise, lack of psychological benefits (Berman et al., 2005; Markland \& Ingledew, 2007), and decreased motivation (Anderson, 2003; Deci \& Ryan, 1985). Women may find that when exercise is motivated by, or results in, a focus on their physical appearance, they feel less inclined to continue. Indeed, Segar et al. (2006; 2008 ; 2010) demonstrated that women whose motives and goals centered on weight loss, health, and/or body-shape participated in less physical activity than women whose motives were not body-related. Stelan et al. (2003) supported this conclusion from the opposite point of view: women who reported exercising for enjoyment and mood enhancement tended to report greater body satisfaction, body esteem, and self-esteem.

Researchers have made the important distinction that while body-motives may be helpful in terms of exercise initiation and short-term exercise goals, increased intrinsic motivation is necessary to sustain long-term exercise and weight loss (Silva, Markland, et al., 2010; Stephan, Boiche, \& Scanff, 2010; Teixeira et al., 2006; Young et al., 2001). Silva, Markland, et al. (2010), for example, found a positive relationship between intrinsic motivation and moderate and vigorous physical activity in overweight or obese women enrolled in a one year trial to increase exercise behavior, supporting the conclusion that intrinsic motivation is related to increased physical activity adherence. Stephan, Boiche and Scanff (2010) also found higher levels of intrinsic motivation and lower levels of amotivation among older women who persisted in an exercise routine compared to women who discontinued exercise routines. However, there was no difference between the groups on reported external regulation. The researchers concluded that these findings were consistent with previous research findings, which suggest that self-determined and internalized motivations are positively associated with persistence (Stephan, Boiche, \& Scanff). A recent study that examined the impact of a year-long, 30 session, weight management intervention grounded in SDT (Silva, Vieira et al., 2010) also supported the above-stated relationship between intrinsic motivation and exercise adherence: women who received the intervention had higher levels of intrinsic motivation to exercise, exercised more, and lost more weight than women in the control group.

Type of motivation clearly has an impact on exercise adherence; exercise-related research also identifies self-efficacyone's feelings about one's aptitude for success in a given domain (Bandura, 1997) — as key factor. Physical self-efficacythe belief that one will be successful in physical or exerciserelated pursuits - can have a significant impact on one's exer- cise intentions and behaviors. Research has shown that the belief that one can effectively meet his or her behavioral intentions, even when presented with personal or situational barriers, is positively correlated with health behavior and health status among adults of various ages (Grembowski et al., 1993). Data on the exercise behavior of older adults demonstrated that physical self-efficacy was not only associated with current behavior, but was also a reliable predictor of future exercise behavior. For example, level of physical self-efficacy significantly discriminated between participants who successfully followed an exercise routine and those who did not, and it predicted exercise adherence nine months later (McAuley et al., 1993). Other studies have supported this trend (Cox et al., 2003; McAuley et al., 1995; Marcus et al., 1992; Wilcox and Storandt, 1996). In their study of 40 - 65 year-old women, Cox et al. (2003) found that physical self-efficacy was directly associated with exercise frequency, and Marcus et al.'s data indicated that greater levels of physical self-efficacy significantly differentiated individuals at greater levels of exercise adherence. Conversely, participants with lower physical self-efficacy reported infrequent exercise behavior. Despite the importance of physical self-efficacy across all age groups, research has shown that physical self-efficacy tends to be higher among younger, compared to older, women (Scharff, Homan, Kreuter, \& Brennan, 1999; Wilcox \& Storandt, 1996).

The positive association between physical self-efficacy and exercise behavior seems to apply to women in various stages of exercise. For example, researchers found that physical selfefficacy discriminates between highly active and moderately active females (Rodgers \& Gauvin, 1998), and is associated with more positive attitudes towards exercise (Wilcox \& Storandt, 1996). Simonavice and Wiggins (2008) investigated the relationship of self-efficacy to the transtheortical stages of change model. They found that self-efficacy increased for each successive stage; it was lowest in the contemplation stage and highest in the maintenance stage. The researchers also found that as self-efficacy increased the individual's perceived barriers to exercise decreased. Also, among inactive, overweight or obese women, physical self-efficacy was associated with weight loss over the course of 4 - 16 months (Teixeira et al., 2006), as well as success in overcoming barriers to exercise adherence (Edmunds et al., 2007).

Exercising regularly affords not only physical health benefits, but also enhances subjective well-being (McAuley et al., 2000). Research findings suggest that small increases in the frequency, duration, and intensity of exercise are related to significant health improvements (Center for Disease Control, 2010), and that over time, exercise adherence is related to enhanced mood and psychological health (Alfermann \& Stoll, 2000; Annesi \& Wescott, 2005; Kelsey et al., 2006; Macdonald \& Palfai, 2008; Matsouka et al., 2005; McAuley et al., 2000; Rocheleau et al., 2004; Rodgers \& Gauvin, 1998). McAuley et al. (2000) demonstrated that participants who engaged in a 6-month exercise program reported significant increases in happiness and satisfaction with life, as well as significant decreases in loneliness. Moreover, there is a positive relationship with exercise behavior and satisfaction with life, such that those with the highest frequency of exercise behavior reported the highest satisfaction with life.

Other research has supported these results. For example, Rodgers and Gauvin (1998) reported data on women who were actively exercising and found that individuals who exercised 
three days a week were more likely to report reduced stress and improved mental health as incentives for exercising than were women who exercised two days per week. Similarly, women who are regular runners reported being motivated by the stress relief and improved mood that exercise affords (Kjelsas \& Augestad, 2003). Matsouka and colleagues (2005) found that participants who exercised three times per week had significantly more positive mood than those who exercised only once per week, or not at all. Janisse, Nedd, Escamilla, and Nies (2004) found that physical activity was a predictor of positive mood for women who had just started a walking program. Finally, the literature contains other evidence that exercise participation is associated with more positive affect and positive coping behavior (Kelsey et al., 2006), improvements in physical self-concept, greater self-esteem, and well-being, as well as less negative self-worth, and fewer psychosomatic complaints (Alfermann \& Stoll, 2000).

The current study adds to the research cited in a 2010 publication by Stephen, Boiche and Scanff, in which the authors examined differences in adherent and non-adherent women's motivation for exercise. While their investigation focused on older women (60 - 88 years old) who were enrolled in an organized physical activity program, and included data from a one-time assessment of motivation for exercise, health status, and self-reported physical activity levels, the current study included data from younger women $(18-65$ years old) which were collected weekly for four weeks. In addition, this study examines differences between adherent and non-adherent women regarding physical self-efficacy and mood (i.e., positive affect and satisfaction with life).

Given the findings reported in previous studies, it was hypothesized that individuals who were non-adherent to their exercise goals would be more likely to report external motives, while individuals who were adherent to their exercise goals would be more likely to report internal, self-determined motives. It was also expected that adherent women would report higher levels of physical self-efficacy, positive affect, and satisfaction with life at each time point, and that their scores would increase or remain stable across time.

\section{Methods}

\section{Participants}

Sixty-four female participants completed the online surveys detailed below. Participants ranged in age from 18 to 65 . Nearly $80 \%$ identified as White, $9.4 \%$ as African American, $4.7 \%$ as Hispanic, $4.7 \%$ as Asian American, and $1.6 \%$ as other. Twenty-eight percent of participants were recruited through flyers posted at university and community fitness centers, and the remaining $72 \%$ were recruited through electronic ads posted on www.Craigslist.com. These advertisements called for adults interested in participating in a study on motivation and exercise, and indicated that there would be two monetary raffle prizes. All participants were required to be 18 years or older and involved in some form of self-regulated exercise.

\section{Instrumentation}

\section{"Welcome Survey"}

Participants reported their sex, age, ethnicity, and a specific exercise goal, in days per week, which they aimed to meet for each of the four weeks of the study.
The Exercise Motivation Inventory-2 (EMI-2)

The EMI-2 is a 51 -item scale administered to assess the degree to which participants endorse specific motivational factors. Participants answered each item on a Likert-type scale, ranging from $0=$ not at all true for me to 5 = very true for me (Markland \& Ingledew, 1997). They received an average score for each of 14 subscales, which fall under five major scales. The Cronbach's alpha, mean, and standard deviation for each of these five scales in the current sample were: psychological motives $(\alpha=0.92, M=50.40, S D=13.78)$; interpersonal motives $(\alpha=0.93, M=19.36, S D=14.44)$; health motives $(\alpha=$ $0.80, M=28.33, S D=7.26)$; body motives $(\alpha=0.87, M=$ $30.65, S D=7.96)$; and fitness motives $(\alpha=0.84, M=27.20, S D$ $=5.73)$.

The Physical Self-Efficacy Scale (PSES)

The PSES is a five-item scale used to assess participants' beliefs in their ability to overcome specific barriers to maintaining their exercise intentions (Schwarzer \& Renner, 2005). Participants answered each item on a Likert-type scale, ranging from $1=$ very uncertain to $4=$ very certain. The Cronbach's alpha, mean, and standard deviation for the current sample were: $\alpha=$ $0.89, M=13.56, S D=3.61$.

The Positive and Negative Affect Schedule (PANAS)

The PANAS is a 20 -item scale that was used to assess participants' affective well-being (Watson, Clark, \& Tellegen, 1998). Ten items comprise the positive affect subscale; the other 10 items comprise the negative affect subscale. Participants answered each item on a Likert-type scale, ranging from $1=$ very slightly or not at all to $5=$ extremely. The Cronbach's alpha, mean, and standard deviation for each of the scales in the current sample were: positive affect: $\alpha=0.90, M=34.66, S D=$ 7.15 and negative affect: $\alpha=0.90, M=22.15, S D=7.81$.

The Satisfaction with Life Scale (SWLS)

The SWLS is a five-item scale that was used to assess participants' global judgment of their satisfaction in various life domains (Diener et al., 1985). Participants answered each item on a Likert-type scale, ranging from $1=$ strongly disagree to 7 = strongly agree. The Cronbach's alpha, mean, and standard deviation in the current sample were: $\alpha=0.93, M=22.72, S D=$ 7.54 .

\section{"Weekly Survey"}

Participants reported a) the days of the week they exercised, b) the duration of exercise on each day, c) a subjective rating of their exercise intensity (low, moderate, high), and d) a subjective stress rating of their week, ranging from $0=$ not at all stressful to $10=$ extremely stressful.

\section{Procedure}

This project was approved by the Human Subjects Committee at the educational institution of its authors. After participants gave informed consent electronically, they were directed to the "Welcome Survey", detailed above, which was created online at www.SurveyMonkey.com. For each of the following four weeks, participants received an email containing the link to the "Weekly Survey", detailed above, which they completed promptly.

\section{Results}

Adherence was determined based on a calculation of the difference between a participant's reported exercise goal and her average weekly exercise. Because reported goals were sub- 
tracted from average weekly exercise, a score greater than or equal to zero indicated that a participant met or exceeded her goal, while a score less than zero indicated that a participant failed to meet her goal. Of the 64 females, exactly $50 \%$ met or exceed their goals. An independent-samples $t$-test indicated that there was no difference between adherents and non-adherents in terms of goals set, $t(61)=-1.28, p=0.21$; adherents $M=4.39$, $S D=1.20$; non-adherents $M=4.78 ; S D=1.24$. In addition, there was not a significant difference in the median age between the adherent group ( $M d n=27$ years) and the non-adherent group $(M d n=26.5$ years $)$.

A Pearson correlation of participants' motives for exercise and their exercise consistency across the four-week data collection period indicated that motives were largely unrelated to exercise consistency. Body-related motives were the only significant correlate, $r=-0.30, p=0.02$, indicating that participants who reported greater body-related motives were less consistent in their week-to-week exercise behavior.

An independent-samples $t$-test was performed to assess differences between adherents' and non-adherents' motives for exercise. Mean comparisons indicated that compared to adherents, non-adherents reported significantly greater health-related and body-related motives for exercise, $t(62)=-2.04, p=0.05$; $t(62)=-2.07, p=0.04$, respectively (see Table 1).

An independent-samples $t$-test was performed to assess differences between adherents and non-adherents on physical self-efficacy, positive affect, and satisfaction with life, as reported by participants in the "Welcome Survey" at the beginning of the data collection period. Contrary to expectation, mean comparisons indicated that adherents reported significantly lower physical self-efficacy, $t(62)=-2.36, p=0.02$; positive affect, $t(62)=-2.07, p=0.04$; and satisfaction with life, $t(62)=-2.74, p=0.01$ (see Table 1). Of note, these factors were significantly correlated with each other among adherents and non-adherents alike (see Table 2).

To assess change across time, a $2 \times 2$ (group $\times$ time) repeated measures ANOVA was conducted for self-efficacy, positive affect, and satisfaction with life. Results indicated a significant group $\times$ time interaction for self-efficacy, $F(1,62)=9.75, p<$ 0.01 . Follow-up comparisons indicated that the adherents experienced a significant increase in self-efficacy across time, $F$

Table 1.

Exercise motives and psychological factors.

\begin{tabular}{|c|c|c|c|c|c|c|c|c|}
\hline & \multicolumn{4}{|c|}{ Adherents } & \multicolumn{4}{|c|}{ Non-Adherents } \\
\hline & \multicolumn{4}{|c|}{$(\mathrm{n}=32)$} & \multicolumn{4}{|c|}{$(\mathrm{n}=32)$} \\
\hline & \multicolumn{2}{|c|}{ Beginning } & \multicolumn{2}{|c|}{ End } & \multicolumn{2}{|c|}{ Beginning } & \multicolumn{2}{|c|}{ End } \\
\hline & Mean & SD & Mean & $\mathrm{SD}$ & Mean & SD & Mean & $\mathrm{SD}$ \\
\hline $\begin{array}{l}\text { Health-related } \\
\text { Motives }\end{array}$ & $12.31_{\mathrm{a}}$ & 3.36 & - & & $13.75_{\mathrm{b}}$ & 2.15 & - & - \\
\hline $\begin{array}{c}\text { Body-related } \\
\text { Motives }\end{array}$ & $11.00_{\mathrm{a}}$ & 4.30 & - & & $12.97_{\mathrm{b}}$ & 3.24 & - & - \\
\hline $\begin{array}{c}\text { Physical } \\
\text { Self-Efficacy }\end{array}$ & $11.63_{\mathrm{a}, 1}$ & 5.45 & $14.22_{2}$ & 3.34 & $14.22_{b}$ & 3.00 & 12.94 & 4.97 \\
\hline Positive Affect & $30.47_{\mathrm{a}, 1}$ & 12.42 & $38.06_{2}$ & 9.60 & $35.59_{b}$ & 6.47 & 34.28 & 11.73 \\
\hline $\begin{array}{l}\text { Satisfaction } \\
\text { with Life }\end{array}$ & $18.31_{\mathrm{a}, 1}$ & 10.23 & $23.25_{2}$ & 7.75 & $24.28_{b}$ & 6.89 & 22.13 & 9.12 \\
\hline
\end{tabular}

Note: In a given row, means with subscript (b) are significantly larger than means with subscript (a) at $p<0.05$. Within groups, in any given row, means with subscript (2) are significantly larger than means with subscript (1) at $p<0.05$.
Table 2.

Physical self-efficacy, positive affect, and satisfaction with life.

\begin{tabular}{lccccccc}
\hline & \multicolumn{3}{c}{ Beginning of the Study } & \multicolumn{3}{c}{ End of the Study } \\
\hline & 1 & 2 & 3 & 1 & 2 & 3 \\
\hline 1) Physical Self-Efficacy & - & $0.45^{* *}$ & 0.32 & - & $0.50^{* *}$ & $0.62^{* *}$ \\
2) Positive Affect & $0.67^{* *}$ & - & $0.48^{* *}$ & $0.48^{* *}$ & - & $0.53^{* *}$ \\
3) Satisfaction with Life & $0.65^{* *}$ & $0.73^{* *}$ & - & 0.11 & $0.51^{* *}$ & - \\
\hline
\end{tabular}

Note. Correlations among the adherent group are below the diagonal in each matrix, and those for the non-adherent group are above the diagonal in each matrix. ${ }^{* *}$ Significant at $p<0.01$

$(1,31)=8.00, p<0.01$, while the non-adherents did not, $F(1$, $31)=1.49, p=0.23$. Similar results were found for positive affect and satisfaction with life. For positive affect, the overall repeated measures ANOVA indicated a significant group $\mathrm{x}$ time interaction, $F(1,62)=6.87, p<0.05$, and follow-up comparisons indicated that adherents experienced a significant increase in positive affect over time, $F(1,31)=8.31, p<0.01$, while non-adherents did not, $F(1,31)=2.31, p=0.21$. Finally, the group $\mathrm{x}$ time interaction was also significant for satisfaction with life, $F(1,62)=7.57, p<0.01$. There was a significant increase in satisfaction with life among adherents, $F(1,31)=$ $8.38, p<0.01$, and there was no significant change in satisfaction with life among non-adherents, $F(1,31)=2.06, p=0.16$. Ratings of physical self-efficacy, positive affect, and satisfaction with life at the end of the study were also significantly correlated among adherents and non-adherents alike (see Table 2).

An independent-samples $t$-test was also performed to assess group differences in the ratings of physical self-efficacy, positive affect, and satisfaction of life at the end of the data collection period. Mean comparisons indicated that adherents and non-adherents did not differ on their ratings of these three variables at the end of the four-week data collection period: physical self-efficacy, $t(62)=1.21, p=0.23$; positive affect, $t(62)=$ $1.41, p=0.16$; and satisfaction with life, $t(62)=0.53, p=0.60$. However, at this time, adherents' scores were greater than nonadherents' score (though, not statistically significantly so) on each of these three variables (see Table 1).

\section{Discussion}

Based on previous empirical findings, it was hypothesized that there would be differences in the motivation to exercise expressed by adherent and non-adherent female exercisers in this study. Specifically, it was expected that adherent women would be more likely to express intrinsic motivation, while non-adherent women would be more likely to identify extrinsic motives for exercising. The results from the current study partially supported this hypothesis. Compared to adherent women, non-adherent women were more likely to endorse body-related and health-related motives for exercising; however, the results did not indicate that adherent women were more likely to express intrinsic motives for exercising. Further confirming the difference found related to extrinsic motives, the data also showed that overall, body-related motives were negatively associated with exercise consistency. Thus, women who reported greater body-related motives for exercising were less consistent in their exercise behavior over the course of the four-week study, and they were less likely to meet their own exercise goals during that time period. It is relevant to note that adherent 
women's success at meeting their exercise-related goals cannot be attributed to them setting lower goals. In fact, adherence was unrelated to goals, and adherent women were equally ambitious as non-adherent women in their initially-stated goals.

These findings are important for understanding types of motives that may or may not encourage women to persist in exercising. While society often uses body-related motives to promote exercise (Blaine \& McElroy, 2002; Prichard \& Tiggemann, 2008), the current results suggest that these external pressures may thwart women's efforts towards exercise adherence and consistency. Further, the results seem to support Deci and Ryan's (1985) theory of self-determination. Specifically, when individuals are motivated primarily by external influence, as seen among the women in this study who reported greater body-related and health-related motives, they are less likely to persist in meeting their exercise-related intentions. These findings provide additional support for the previous research, which has suggested that motives that do not support intrinsic motives are less likely to be associated with exercise adherence (Ryan \& Deci, 2000; Ryan et al., 1997; Segar et al., 2006).

The current study and the study by Stephan, Boiche and Scanff (2010) are significant for their support of the theory of self-determination: the findings from the current study identified significant differences between adherent and non-adherent women with regards to external motivation, while the findings from Stephen et al. identified significant differences between adherent and non-adherent women with regards to intrinsic motivation.

The current findings regarding physical self-efficacy, positive affect, and satisfaction with life may shed additional light on persistence and adherence to exercise-related goals. It was hypothesized that adherent women would report higher levels of these three constructs at each time point, and that their scores would increase or remain stable across time. The results of the current study were partially consistent with these hypotheses. Contrary to the hypothesis, adherent women actually reported lower levels of physical self-efficacy, positive affect, and satisfaction with life when compared to non-adherent women at the outset of the study. This finding is inconsistent with previous research findings, which suggest that higher levels of physical self-efficacy are related to current adherence and predictive of future adherence (Cox et al., 2003; McAuley et al., 1995; McAuley et al., 1993; Marcus et al., 1992; Wilcox \& Storandt, 1996). One possible explanation is that adherent women were more cautious in the reporting of their self-efficacy and other mood scores, which led to the lower reporting of scores at the outset. Further, these women may have felt more confident after adhering to their goals over the four weeks, which led to the increase in self-efficacy and mood scores at the end.

Consistent with the hypothesis, adherent women showed significant increases in reported feelings of psychological wellbeing over time. Over the course of the four-week study, there was a significant increase in physical self-efficacy, positive affect, and satisfaction with life among adherent women. Thus, as they continued to meet their goals, they felt an increased sense of psychological well-being. From this data, it is difficult to determine if increased psychological well-being resulted in greater exercise adherence, or vice versa. Also, there is a possibility that these factors could share bi-directional relationships. Nevertheless, the significant and positive increase they reported in these factors is notable, particularly as they relate to the women's exercise adherence.
Furthermore, it can be certain that this finding is not due to a ceiling effect for the non-adherent group. The non-adherents' mean scores for physical self-efficacy, positive affect, and satisfaction with life at the beginning of the study were 11.63 (on a scale of 5 to 20), 24.28 (on a scale of 5 to 35 ), 30.40 (on a scale of 10 to 50 ), respectively. Thus, they had adequate room for potential improvement.

It is possible that the findings from the current study that are different from previous research might be due to the measures used, the duration of the study, and/or the sample demographics. As such, future research should be conducted to attempt to confirm both pieces of the theory of self-determination in one sample by examining different participant groups, lengths between assessments, and measurement tools.

Overall, the results from this study provide two key messages: 1) that body-related and health related pressures have the potential to detract from women's abilities to persist towards exercise adherence, and 2) that psychological well-being improves with exercise adherence. It may be more helpful to women if societal messages aimed to promote physical fitness focusing on factors that are more intrinsic, such as competence, autonomy, and relatedness. If this shift helped more women to approach their goals with greater self-determination, the effects could be profound-women would likely persist and succeed at meeting their exercise-related goals more often, and they would experience increased physical self-efficacy, positive affect, and satisfaction with life.

\section{REFERENCES}

Alfermann, D., \& Stoll, O. (2000). Effects of physical exercise on self-concept and well-being. International Journal of Sport Psychology, 31, 47-65.

Anderson, C. B. (2003). When more is better: Number of motives and reasons for quitting as correlates of physical activity in women. Health Education Research, 18, 525-537. http://dx.doi.org/10.1093/her/cyf041

Annesi, J. J., \& Wescott, W. L. (2005). Age as a moderator of relations of physical self-concept and mood changes associated with 10 weeks of programmed exercise in women. Perceptual and Motor Skills, 101, 840-844. http://dx.doi.org/10.2466/pms.101.3.840-844

Bandura, A. (1977). Social learning theory. Englewood Cliffs, NJ: Prentice-Hall.

Berman, E., Kerr, G., \& De Souza, M. J. (2005). A qualitative examination of weight concerns, eating, and exercise behaviors in recreational exercisers. Women in Sport and Physical Activity Journal, 14, 24-38.

Blaine, B., \& McElory, J. (2002). Selling stereotypes: Weight loss infomercials, sexism, and weightism. Sex Roles, 46, 351-357. http://dx.doi.org/10.1023/A:1020284731543

Cash, T. F., Novy, P. L., \& Grant, J. R. (1994). Why do women exercise? Factor analysis and further validation of The Reasons for Exercise Inventory. Perceptual and Motor Skills, 78, 539-544. http://dx.doi.org/10.2466/pms.1994.78.2.539

Centers for Disease Control (2008). Physical Activity for Everyone. http://www.cdc.gov/physicalactivity/everyone/guidelines/index.html

Cox, K. L., Gorely, T. J., Puddey, I. B., Burke, V., \& Beilin, L. J. (2003). Exercise behavior change in 40 to 65 -year-old women: The SWEAT study. British Journal of Health Psychology, 8, 477-495. http://dx.doi.org/10.1348/135910703770238329

Deci, E. L., \& Ryan, R. M. (1985). Intrinsic motivation and self-determination in human behavior. New York: Plenum. http://dx.doi.org/10.1007/978-1-4899-2271-7

Diener, E., Emmons, R. A., Larsen, R. J., \& Griffin, S. (1985). The satisfaction with life scale. Journal of Personality Assessment, 49, 71-75. http://dx.doi.org/10.1207/s15327752jpa4901_13 
Dishman, R. K. (1990). Determinants of participation in physical activity. In C. Bouchard, R. Shephard, T. Stephens, J. Sutton, \& B. McPherson (Eds.), Exercise, fitness, and health (pp. 75-102). Champaign, IL: Human Kinetics.

Edmunds, J., Ntoumanis, N., \& Duda, J. L. (2007). Adherence and well-being in overweight and obese patients referred to an exercise on prescription scheme: A self-determination theory perspective. Psychology of Sport and Exercise, 8, 722-740. http://dx.doi.org/10.1016/j.psychsport.2006.07.006

Finkenberg, M. E., DiNucci, J. M., McCune, S. L., \& McCune, E. D. (1994). Analysis of course type, gender, and personal incentives to exercise. Perceptual and Motor Skills, 78, 155-159.

http://dx.doi.org/10.2466/pms.1994.78.1.155

Frederick, C. M., \& Morrison, C. S. (1996). Social physique anxiety: Personality constructs, motivations, exercise attitudes and behaviors. Perceptual and Motor Skills, 82, 963-972.

http://dx.doi.org/10.2466/pms.1996.82.3.963

Frederick, C. M., Morrison, C., \& Manning, T. (1996). Motivation to participate, exercise affect, and outcome behaviors towards physical activity. Perceptual and Motor Skills, 82, 691-701. http://dx.doi.org/10.2466/pms.1996.82.2.691

Gill, K., \& Overdorf, V. (1994). Incentives for exercise in younger and older women. Journal of Sport Behavior, 17, 87-97.

Grembowski, D., Patrick, D., Diehr, P., Durham, M., Ber-Esford, S., Kay, E., et al. (1993). Self-efficacy and health behavior among older adults. Journal of Health and Social Behavior, 34, 89-104. http://dx.doi.org/10.2307/2137237

Izquierdo-Porrera, A. M., Powell, C. C., Reiner, J., \& Fontaine, K. R. (2002). Correlates of exercise adherence in an African American church community. Cultural Diversity and Ethnic Minority Psychology, 8, 389-394. http://dx.doi.org/10.1037/1099-9809.8.4.390

Kelsey, K. S., DeVellis, B. M., Begum, M., Belton, L., \& Hooten, E. G. (2006). Positive affect, exercise and self-reported health in blue-collar women. American Journal of Health Behavior, 30, 199-207. http://dx.doi.org/10.5993/AJHB.30.2.9

Kilpatrick, M., Hebert, E., \& Bartholomew, J. (2005). College students' motivation for physical activity: Differentiating men's and women's motives for sport participation and exercise. Journal of American College Health, 54, 87-94.

http://dx.doi.org/10.3200/JACH.54.2.87-94

Kjelsas, E., \& Augestad, L. B. (2003). Gender differences in competitive runners and their motive for physical activity. The European Journal of Psychiatry, 17, 157-171.

Macdonald, A., \& Palfai, R. (2008). Predictors of exercise behavior among university student women: Utility of a goal-systems/selfregulation theory framework. Personality and Individual Differences, 44, 921-931. http://dx.doi.org/10.1016/j.paid.2007.10.024

Marcus, B. H., Selby, V. C., Niaura, R. S., \& Rossi, J. S. (1992). Selfefficacy and the stages of exercise behavior change. Research Quarterly of Exercise and Sport, 63, 60-66. http://dx.doi.org/10.1080/02701367.1992.10607557

Markland, D., \& Ingledew, D. K. (2007). The relationship between body mass and body image and relative autonomy for exercise among adolescent males and females. Psychology of Sport and Exercise, 8, 836-853. http://dx.doi.org/10.1016/i.psychsport.2006.11.002

Markland, D., \& Ingledew, D. K. (1997). The measurement of exercise motives: factorial validity and invariance across gender of a revised Exercise Motivations Inventory. British Journal of Health Psychology, 2, 361-376.

http://dx.doi.org/10.1111/j.2044-8287.1997.tb00549.x

Matsouka, O., Kabitsis, C., Harahousou, Y., \& Trigonis, I. (2005). Mood alterations following an indoor and outdoor exercise program in healthy elderly women. Perceptual and Motor Skills, 100, 707-715. http://dx.doi.org/10.2466/PMS.100.3.707-715

McAuley, E., Lox, C., \& Duncan, T. E. (1993). Long-term maintenance of exercise, self-efficacy, and physiological change in older adults. Journal of Gerontology, 48, 218-224.

http://dx.doi.org/10.1093/geronj/48.4.P218

McAuley, E., Bane, S. M., \& Mihalko, S. L. (1995). Exercise in middle-aged adults: self-efficacy and self-presentational outcomes. Preventive Medicine, 24, 319-328. http://dx.doi.org/10.1006/pmed.1995.1053

McAuley, E., Blissmer, B., Marquez, D. X., Jerome, G. J., Kramer, A. F., \& Katula, J. (2000). Social relations, physical activity, and wellbeing in older adults. Preventive Medicine, 31, 608-617. http://dx.doi.org/10.1006/pmed.2000.0740

Prichard, I., \& Tiggemann, M. (2008). Relations among exercise type, self-objectification, and body image in the fitness centre environment: The role of reasons for exercise. Psychology of Sport and Exercise, 9, 855-866. http://dx.doi.org/10.1016/j.psychsport.2007.10.005

Rocheleau, C. A., Webster, G. D., Bryan, A., \& Frazier, J. (2004). Moderators of the relationship between exercise and mood changes: Gender, exertion level, and workout duration. Psychology \& Health, 19, 491-506. http://dx.doi.org/10.1080/08870440310001613509

Rodgers, W. M., \& Gauvin, L. (1998). Heterogeneity of incentives for physical activity and self-efficacy in highly active and moderately active women exercisers. Journal of Applied Social Psychology, 28, 1016-1029. http://dx.doi.org/10.1111/j.1559-1816.1998.tb01665.x

Ryan, R. M., \& Deci, E. L. (2000). Self-determination theory and the facilitation of intrinsic motivation, social development, and well-being. American Psychologist, 55, 68-78. http://dx.doi.org/10.1037/0003-066X.55.1.68

Ryan, R. M., \& Deci, E. L. (2000). Self-determination theory and the facilitation of intrinsic motivation, social devel-opment, and wellbeing. American Psychologist, 55, 68-78. http://dx.doi.org/10.1037/0003-066X.55.1.68

Ryan, R. M., Frederick, C. M., Lepes, D., Rubio, N., \& Sheldon, K. M. (1997). Intrinsic motivation and exercise adherence. International Journal of Sport Psychology, 28, 335-354.

Sallis, J. F., Hovell, M. F., \& Hofstetter, C. R. (1992). Predictors of adoption and maintenance of vigorous physical activity in men and women. Preventive Medicine, 21, 237-251. http://dx.doi.org/10.1016/0091-7435(92)90022-A

Scharff, D. P., Homan, S., Kreuter, M., \& Brennan, L. (1999). Factors associated with physical activity in women across the life span: Implications for program development. Women and Health, 29, 115-134. http://dx.doi.org/10.1300/J013v29n02 08

Schuler, P. B., Broxon-Hutcherson, A., Philipp, S. F., Ryan, S., Isosaari, R. M., \& Robinson, D. (2004). Body-shape perceptions in older adults and motivations for exercise. Perceptual and Motor Skills, 98, 1251-1260.

Segar, M. L., Eccles, J. S., \& Richardson, C. R. (2008). Type of physiccal activity goal influences participation in healthy midlife women. Women's Health Issues, 18, 281-291.

http://dx.doi.org/10.1016/j.whi.2008.02.003

Segar, M., Spruijt-Metz, D., \& Nolen-Hoeksema, S. (2006). Go figure? Body-shape motives are associated with decreased physical activity participation among midlife women. Sex Roles, 54, 175-187. http://dx.doi.org/10.1007/s11199-006-9336-5

Schwarzer, R., \& Renner, B. (2005). Health-specific self-efficacy scales. 7-10. http://userpage.fu-berlin.de/ health/healself.pdf

Silva, M. N., Markland, D., Vieira, P. N., Coutinho, S. R., Caraca, E. V., Palmeria, A. L. et al. (2010). Helping overweight women become more active: Need support and motivational regulations for different forms of physical activity. Psychology of Sport and Exercise, 11, 591601. http://dx.doi.org/10.1016/j.psychsport.2010.06.011

Silva, M. N., Vieira, P. N., Coutinho, S. R., Minderico, C. S., Matos, M. G., Sardinha, L. B., \& Teixeira, P. J. (2010). Using self-determination theory to promote physical activity and weight control: A randomized controlled trial in women. Journal of Behavioral Medicine, 33, 110122. http://dx.doi.org/10.1007/s10865-009-9239-y

Simonavice, E. M., \& Wiggins, M. S. (2008). Exercise barriers, self-efficacy, and stages of change. Perceptual and Motor Skills, 107, 946-950. http://dx.doi.org/10.2466/pms.107.3.946-950

Stephen, Y., Boiche, J., \& Scanff, C. L. (2010). Motivation and physical activity behaviors among older women: A self-determination perspective. Psychology of Women Quarterly, 34, 339-348. http://dx.doi.org/10.1111/j.1471-6402.2010.01579.x

Strelan, P., Mehaffey, S. J., \& Tiggemann, M. (2003). Self-objectification and esteem in young women: The mediating role of reasons for exercise. Sex Roles, 48, 89-95.

http://dx.doi.org/10.1023/A:1022300930307 


\section{S. S. KOHLSTEDT ET AL.}

Teixeira, P. J., Going, S. B., Houtkooper, L. B., Cussler, E. C., Metcalfe, L. L., Blew, R. M., Sardinha, L. B., \& Lohman, T. G. (2006). Exercise motivation, eating, and body image variables as predictors of weight control. Medicine and Science in Sports and Exercise, 38, 179-188. http://dx.doi.org/10.1249/01.mss.0000180906.10445.8d

Tiggemann, M., \& Williamson, S. (2000). The effect of exercise on body satisfaction and self esteem as a function of gender and age. Sex Roles, 43, 119-127. http://dx.doi.org/10.1023/A:1007095830095

Wankel, L. M. (1993). The importance of enjoyment to adherence and psychological benefits from physical activity. International Journal of Sport Psychology, 24, 151-169.

Watson, D., Clark, L. A., \& Tellegen, A. (1988). Development and validation of brief measures of positive and negative affect: The PANAS scales. Journal of Personality and Social Psychology, 54, 1063-1070.

Wilcox, S., \& Storandt, M. (1996). Relations among age, exercise, and psychological variables in a community sample of women. Health Psychology, 15, 110-113.

http://dx.doi.org/10.1037/0278-6133.15.2.110

Wilson, P. M., \& Rodgers, W. M. (2004). The relationship between perceived autonomy support, exercise regulations, and behavioral intentions in women. Psychology of Sport and Exercise, 5, 229-242. http://dx.doi.org/10.1016/S1469-0292(03)00003-7

Young, D. R., Gittelsohn, J., Charleston, J., Felx-Aaron, K., \& Appel, L. J. (2001). Motivations for exercise and weight loss among AfricanAmerican women: Focus group results and their contribution towards program development. Ethnicity \& Health, 6, 227-245.

http://dx.doi.org/10.1080/13557850120078143 